\begin{tabular}{|l|l|l||}
\hline \multicolumn{2}{|c|}{ PublisherInfo } \\
\hline \hline PublisherName & $:$ & BioMed Central \\
\hline \hline PublisherLocation & $:$ & London \\
\hline \hline PublisherImprintName & $:$ & BioMed Central \\
\hline \hline
\end{tabular}

\title{
Role of ERK and NF-?B pathways in osteoclasts
}

\begin{tabular}{|l|l|l||}
\hline \multicolumn{2}{|c|}{ ArticleInfo } \\
\hline \hline ArticleID & $:$ & 199 \\
\hline \hline ArticleDOI & $:$ & $10.1186 /$ ar-2000-66791 \\
\hline \hline ArticleCitationID & $:$ & 66791 \\
\hline \hline ArticleSequenceNumber & $:$ & 156 \\
\hline \hline ArticleCategory & $:$ & Paper Report \\
\hline \hline ArticleFirstPage & $:$ & 1 \\
\hline \hline ArticleLastPage & $:$ & 4 \\
\hline \hline & & RegistrationDate : 2000-3-17 \\
\hline ArticleHistory & $:$ & OnlineDate \\
\hline ArticleCopyright & $:$ & Current Science Ltd2000-17 \\
\hline \hline ArticleGrants & $:$ & \\
\hline \hline ArticleContext & $:$ & 130753311 \\
\hline \hline
\end{tabular}




\section{Keywords}

Apoptosis, ERK, NF-?B, Osteoclast, Ras

\section{Context}

The signalling pathways regulating osteoclast survival are not well known, although a potential candidate is the Ras/ERK pathway, known to control apoptosis in haematopoietic cells. In this pathway Raf, recruited to the plasma membrane by activated Ras where it activates MAPK/ERK kinase (MEK), which in turn activates extracellular signal-regulated kinase (ERK). NF-?B is a cytoplasmic transcription factor which is activated following phosphorylation of its inhibitory subunit, I?B by I?B kinase (IKK), which results in the degradation of I\&\#954. It has recently been reported that NF-?B is involved in the promotion of osteoclast survival by interleukin (IL)-1, and that mice lacking NF-?B are osteopetrotic because of a failure in the generation of mature osteoclasts. This suggests that NF-?B is important for both osteoclast formation and osteoclast survival. To clarify the role that the Ras/ERK and NF-?B pathways play in osteoclast survival, by using adenoviral transfection of osteoclasts with mutant forms of components of these signalling pathways.

\section{Significant findings}

Almost all osteoclasts transfected with RasDN (which inhibited basal activity of ERK) died within 18 $\mathrm{h}$ of purification, compared to $70 \%$ of control osteoclasts. This was caused by induction of apoptosis, since DNA isolated from these cells was fragmented. PD98059, a specific ERK inhibitor, also reduced osteoclast survival, whereas expression of MEKCA enhanced osteoclast survival, and prevented the deleterious effect of RasDN on survival. IL-1a was shown to stimulate a rapid and transient increase in ERK activity in osteoclasts, which was partially prevented in osteoclasts expressing RasDN. IL-1a promotes nuclear translocation of NF-?B by stimulating degradation of I?B, an effect unaltered in osteoclasts expressing RasDN. Expression of either IKKDN, which resulted in NF-?B translocation and activation, or of IKKCA, which resulted in slight activation of NF-?B, did not affect the survival of osteoclasts with or without IL-1? stimulation. Resorptive activity of osteoclasts was inhibited by expression of IKKDN and stimulated by expression of IKKCA, whereas the expression of either RasDN or MEKCA were without effect. Moreover, expression of IKKDN inhibited resorption stimulated by 
IL-1?. Colony-stimulating factor-1 (CSF-1), which maintains survival of osteoclasts without affecting their activity, stimulated transient expression of ERK but had no effect on NF-?B activity.

\section{Comments}

This paper follows earlier work by Chen et al (J Biol Chem 1998, 273:19809-19816 [Abstract]) on the role of the Ras/ERK pathway in osteoclasts, demonstrating its involvement in regulating osteoclast survival, which suggests that this pathway could be a novel target for anti-resorptive therapy. However, since Ras proteins are farnesylated (with the exception of K-Ras), and it is geranylgeranylated proteins, rather than farnesylated proteins, that appear to regulate survival of osteoclasts (Reszka et al, J Biol Chem 1999, 274:34967-34973 [Abstract]), this result is slightly surprising. Determining which Ras proteins are expressed in osteoclasts may help resolve this issue. This paper also supports previous reports demonstrating a role for NF-?B in osteoclast activity. However, the apparent lack of a role for NF-?B in regulating osteoclast survival contrasts with the findings of Jimi et al (J Biol Chem 1998, 273:8799-8805 [Abstract]). Moreover, it is known that receptor activator of NF-?B ligand (RANKL), which activates NF-?B, can promote osteoclast survival, although it is possible that this could be through a pathway other than NF-?B. These conflicting results suggest that further work is necessary to determine the precise role that NF-?B plays in osteoclasts.

\section{Methods}

Osteoclast-like cells were generated using a co-culture of primary mouse osteoblasts and mouse marrow cells in the presence of 1 ?,25( $\mathrm{OH})_{2} \mathrm{D}_{3}$ and prostaglandin $\mathrm{E}_{2}\left(\mathrm{PGE}_{2}\right)$. Recombinant adenoviral vectors carrying genes under the control of the $\mathrm{CAG}$ promoter were used to express mutant forms (dominant-negative or constitutively active, denoted DN and CA respectively) of Ras, MEK and IKK2 in these osteoclasts. Expression of these proteins was detected by western blotting. ERK activity in lysates was measured either by immunoprecipitating with an antibody to ERK2 and assaying for kinase activity, or by western blotting using an antibody to phosphorylated ERK. The role of ERK was also investigated using the specific inhibitor PD98059. Apoptosis was determined by agarose electrophoresis of extracted DNA and by TUNEL assay to detect DNA fragmentation, whilst cell survival was quantified by counting morphologically normal cells following staining for tartrate-resistant acid phophatase. Activity of NF-?B was determined either by immunolocalisation using an antibody to the p65 subunit of NF-?B, by western blotting using an antibody to I?B or by electrophoretic mobility shift assays to detect binding of NF-?B from lysates to a $\left[{ }^{32} \mathrm{P}\right]$-labelled oligonucleotide probe. Osteoclast activity was assessed using purified osteoclasts incubated on dentine, followed by analysis of resorption pits using light microscopy. 


\section{References}

1. Miyazaki T, Katagiri H, Kanegae H, Takayanagi H, Sawada Y, Yamamoto A, Pando M, Asano T, Verma I, Oda H, Nakamura K, Tanaka S: Reciprocal role of ERK and NF-?B pathways in survival and activation of osteoclasts. J Cell Biol. 2000, 148: 333-342.

This PDF file was created after publication. 